\title{
Motor Vehicles: Are they emerging threats to Lake Victoria and its Environment?
}

\author{
Joseph L. Awange ${ }^{1}$ and Benard Obera ${ }^{2}$ \\ 1. Department of Spatial Sciences, \\ Division of Resource and Environmental, \\ Curtin University of Technology, Australia. \\ Email: J.awange@curtin.edu.au, Tel:+61-08-92662218 \\ 2. Department of Environment \\ Maseno University, Private Bag, Maseno Kenya.
}

\begin{abstract}
Lake Victoria and its basin supports more than 30 million people, while its fishes are exported the world over. This second largest fresh water body is however experiencing stress due to eutrophication, sedimentation, declining levels and more recently the motor vehicle sector. This contribution examines the general pollution from motor vehicle and gives an in-depth analysis of motor vehicle washing along the lakeshore. The results indicate the water samples from the motor vehicle washing and urban runoff points to be slightly acidic (i.e., average $\mathrm{pH}$ of 6.7 ) and average Total Phosphorus levels of 0.4 and $2.4 \mathrm{ppm}$ respectively. This implies that there was high soap input at these points. The conductivity for the motor vehicle washing points averaged at $150 \mu \mathrm{S} / \mathrm{cm}$, while the urban runoffs point was more varied ranging from below $150 \mu \mathrm{S} / \mathrm{cm}$ to over $400 \mu \mathrm{S} / \mathrm{cm}$ (average $301 \mu \mathrm{S} / \mathrm{cm}$ ). A positive correlation coefficient of more than 0.7 is obtained between the total daily count of vehicles and each of the water quality parameter tested. This signifies a strong correlation between motor vehicle related activities and the pollution of the lake. In general, the motor vehicle industry is found to have a noticeable negative effect on the Lake.
\end{abstract}

Keywords: Lake Victoria, Water, Pollution, Motor Vehicle, Environment

\section{Introduction}

Lake Victoria, a fresh water ecosystem that serves more than 30 million people, and which is also home to various biodiversities is under threat ranging from various sources of pollution to declining water levels. An unnoticed contributor to pollution, however, is the motor vehicle sector. Although pollution from industry, agrochemical factories and farmlands have received fair attention as evidenced in documentations, e.g., Odada (2004), contribution from motor vehicles has received little or no attention if any. This is despite 
the fact that De Langen and Rustica (2001) had already pointed out that motor vehicle transport is the main cause of environmental degradation in some cities.

The importance of this lake to the world has been pointed out by, e.g., Awange and Ong'ang'a (2006). Motor vehicle pollution to the lake however small could lead to chemicals finding their way into fishes. The fact that automobile lubricants could find their way into fishes had been pointed out for instance by Omoregi and Okunsebor (2005). The pollutants from motor vehicles enter the lake waters directly or indirectly. The direct entry of pollutants into the lake occurs through motor vehicle washing that is rampant in various cities surrounding the lake, while the indirect pollution occurs through runoffs. Pollutants from runoffs takes the form of litter generated at the bus termini and along the roads, open shed car repair garages commonly known as 'jua kali', exhaust fumes and oil spills on to the roads. Problems of water quality associated with highway development have been treated in Pitt (2001), while the risk of acidification due to rain and surface runoff has been considered by Silva and Manuweera (2004). In their study of the chemical constituents of surface and rain water, they found that rainwater collected from urban centers with high population densities had moderate concentrations of nitrate, sulphate and chloride ions, and tended to be slightly acidic.

Two Cities and several urban centers surround lake Victoria thus increasing its motor vehicle concentration. Kisumu city in Kenya located at Winam gulf of lake Victoria is the largest urban area on the Kenyan shores of the lake. Together with Kampala and Jinja in Uganda, and Mwanza in Tanzania, they have been blamed for the high pollutant input resulting from both the industries and settlements. The pollution associated with motor vehicles has largely been ignored and assumed to be negligible (see, e.g, . Odada et al. 2004, Aseto and Ong'ang'a 2003). In particular, the increase in the motor vehicle traffic experienced in Kisumu due to its strategic location on the main trans-national highway has contributed to the pollution of the lake. Wastes from Kisumu have found their way into the lake due to poor environmental services and drainage infrastructures that do not provide treatment for runoffs before they reach the Lake. Another high input of pollutants to the Lake in Kisumu, which is emerging as a great threat to the Lake, is the motor vehicle washing at Kichinjoni beach.

Besides the impacts of motor vehicle pollution on the fish of the lake, there is the actual danger of contaminating the drinking water. Wetlands have to be cleared to pave way for motor vehicle washing areas. Motor vehicle washing in the lake also contributes to the destruction of flora and fauna. In contributing towards the conservation of clean environment and the on going studies on water pollution, and Lake Victoria in particular, the present study looks at how motor vehicles in Kisumu (Kenyan) is polluting Lake Victoria waters. Remedial measures are suggested that would be useful for policy formulation. The results of the study highlights pertinent issues which may often be ignored.

The study is mainly presented in two parts. Section 2 looks at indirect pollution of the lake as a result of surface runoff from automobile related related activities. Their pollution impact on the environment and the lake are discussed. Section 3 focuses on direct pollution of the lake as a result of motor vehicle washing. The results are presented in section 4 and discussed in section 5 . The study is concluded in section 6 .

\section{Indirect Pollution: Motor Vehicle Related Activities}

The location of Kisumu City is so strategic in that the western part of Kenya is largely accessed via it. To reach Uganda from Kenya, one passes Kisumu through to Busia border. From Kisumu, Tanzania can be accessed via Migori. It is the largets City directly situated within the lake's surrounding. The volume of the vehicles in some roads of Kisumu during 2004 is summarized in Table 1 (KCEP, 2005), while the congestion is depicted by Figure 1a. Most of the vehicles within the town, and indeed the whole country, 
are of the old generation which cannot run sustainably on unleaded fuel. The high lead content combined with the low combustion efficiency of the old type of engines lead to emission of high volumes of exhaust gasses, which contain semi-combusted fuels combined with worn out engine parts and waste oils, hence high concentration of particulate matter in the air (Figure 1a). These contributes towards atmospheric pollution of the Lake Victoria, leading to further eutrophication. Atmospheric pollution has been shown by LVEMP (2003) to be the leading pollutant of the lake contributing more than $30 \%$. Tamatamah et al. (2005) puts the total atmospheric pollution of Lake Victoria to 55\%. Major motor vehicle related activities which end up polluting the Lake as runoff included; sand transportation from the beaches, bus park, garages (locally known as 'jua kali', translated as hot sun since people work in open areas) and the oil deports or Petrol stations (Figure 2).

Sand harvested within the beach are normally transported using Trucks. These were noted to enhance soil erosion of the roads causing the formation of ruts on the roads. In a study conducted for a duration of three months commencing from 6th November 2005 to 7th February 2006, an average of 14 Lorries transported sand from Usoma beach (the leading sand mining beach in Kisumu). Each lorry carried averagely 119 tones per day. Such rate estimated in a year of 365 days forms 43,435 tones collected from the beach. With these weight, the roads are eroded and fill up with muddy water and eventually end up in the Lake during rainy seasons contributing to sedimentation of the Lake.

In terms of waste being washed by runoff water into the lake, the bus park stands out as the leading contributor. Almost all of the 28,800 commuter vehicles (Matatu) and 1,259 buses listed in Table 1 pass through the bus park. With high rate of unemployment, i.e., Kisumu population is close to 350,000 million people with 30\% unemployment rate (KCDS 2004), most people engage in hawking and food vending at the bus park. The provision for vehicle parking and transport however comes with the need for provision of services for the passenger-generated waste which is not the case for Kisumu. Passenger waste thus result in severe waste problems at the Kisumu bus park, the highways and taxi parking. This has seen the accumulation of both liquid and solid wastes at the termini. With the low waste services in the town, most of the wastes end up in the drains hence blocking them during rainstorms or swept into the lake via these drainage channels as illustrated in Figure 3.

Perhaps the most serious pollutants heading towards the lake comes from the vehicle repair, service and maintenance yards and open shed garages (Jua kali). These garages have mushroomed in several sports close to the lake shore with some having one to two attendants. These garages are popularly visited due to the fact that they offer cheap services. The yards have no provision for waste handling of any kind. This has resulted in used oils being poured on the ground at the point of change, old tires and batteries being dumped at site which eventually find their way into the Lake during runoffs (see, e.g., Figure 4). From these garages, Spray painting of vehicles also contribute to the metal content of the runoff. This is in the form of the fillings from the old paint work (Enamel) before spraying, the actual spraying, and washing of the sprayed vehicles (see, e.g., Figure 5). Welding is the other form of pollution at the Jua Kali garage. Vehicle repairs involve some welding in the body work, as well as the making of other metal products like grills for doors and windows. Welding is done using electric arc welder, oxy acetylene gas, as well as using kerosene burners. The fumes emitted from the welding processes are not only harmful to the welders but to the general public as well as the environment.

The efficiency of most of the vehicles, especially the public transport within the city is also questionable. The vehicles are old and unreliable, leading to frequent breakdowns and accidents. Yitambe et al. (2005) have estimated that $25 \%$ of the road accidents are caused by poor conditions of vehicles. Some of the vehicles even use Jerry cans as the vehicle fuel tank. Most of the public transport vehicles therefore spill oil as well as fuel in the period of their operation (see Figure 6). These oil spills find their way into the Lake during run offs. Oil also finds its way into the Lake from petrol stations and depots (Figure 7). The town has 2 operational oil deports and c.a. 20 petrol stations to supply fuel to the motor vehicles. These 
do not have adequate treatment mechanism for the waste water and oil spills from their sites. Their wastes end up in the common storm water drains or streams and eventually end up into the Lake. Large transit trucks also ferry petroleum products from the depots, through the city center to their destination. The filling up of the trucks and the emptying at the petrol stations are not efficient, oil spills occur at both the source as well as the destination, and are swept into the conventional drainage system.

\section{Direct Pollution: Motor Vehicle Washing in the Lake}

An increasingly popular practice at the beaches today is the motor vehicle washing. The motor vehicle washing history stretches back to the late 1950s. The beach records very high turn over of vehicles of different classes with tens of vehicles washed at the lake every day. In order to ascertain the impact of Kisumu's motor vehicle washing on lake Victoria, we carried out 6 weeks of study between the months of March and April 2005 at Kichinjio beach, a famous fish eating and the leading motor vehicle washing point in lake Victoria. For each of the weeks, water samples from different spots were analyzed for conductivity, $p H$ and Phosphates. Conductivity was selected for water quality analysis since it varies with dissolved particles in the water. In-case of highly conductive substances, e.g., metals, then a higher conductivity is recorded. For low conductive substance, a low conductivity results. Through oil leakage from the vehicles being washed, the lake became polluted by lead. The runoff from the open shed garages also brings with it metallic pollutants (e.g., washed oil containing lead) which could be captured by measuring conductivity. Conductivity therefore analyzes the presence of metals as a result of motor vehicle related activities. By measuring the water $\mathrm{pH}$, the acidity of the lake due to leakage from vehicle batteries is measured. Since detergents contain Phosphorus, and they are used in the actual washing of the vehicles, it was necessary to measure the total Phosphorus (TP). Runoff from garages also contain paints which contain phosphorus substances. The Hach's water testing kit was used in testing these water quality parameters.

Data on the number and type of vehicles washed at the beach was also collected by vehicle counting and analyzed. Vehicle count by category was done within every thirty minutes between $7 \mathrm{am}$ and $7 \mathrm{pm}$ of each sampling day. These categories were private cars, public transport vehicles (known locally as Matatus), buses, canters, lorries and tankers. Enumerators with the data sheet took the data on a twelve-hour basis.

Six water-sampling points were designated along the beach line depending on the activity. Point 1 had an inlet to the lake carrying runoff from open shed garages and bus park, points 2,4 , and 5 were motor vehicle washing places. For control purposes, points 3 and 6 without motor vehicle washing activities were selected. Point 6 was $200 \mathrm{~m}$ from points 4 and 5 to get the readings from undisturbed area. The water samples were collected once a week for six weeks at $6 \mathrm{pm}$, so as to analyze the effect of the day's motor vehicle activities.

\section{Results}

Table 1 and Figures 10-12 present the daily records of the types of the vehicles washed at Kichinjio beach for the sampled period. The results indicate that Public Service Vehicles (normally of 14 seater Nissan type known locally as Matatus) recorded the highest daily average number of vehicles washed at the beach (42\%), followed by the private cars (34\%). Figure 12 presents the daily trend in motor vehicle washing activity during the day. The highest number of vehicles being washed at the beach is indicated to have occurred during lunch hour, with most being private cars. The highest Matatus (Public Service Vehicles) 
count in contrast was recorded after $6 \mathrm{pm}$. Though few, buses and trailer trucks (tankers) were recorded being washed at the site (see, Figure 15). The number of vehicles being washed was fairly constant throughout the period of the study apart from 4th of April when a general low count was recorded in all categories apart from lorries. The 28th of March recorded the highest vehicle counts.

Point 1 for the urban run off and point 6 for the undisturbed shore posted higher conductivity values than the motor vehicle washing points, which posted the lowest conductivity values (Table 4). The urban drain recorded, exceptionally, the highest average phosphate values while the second motor vehicle wash point recorded the lowest. In terms of turbidity, the motor vehicle washing points had the most turbid water compared to the non-motor vehicle washing points, which had the clearest water.

The observations of the various points also indicated that the motor vehicle washing points had the lowest biodiversity evident by the lack of birds, plants or water life visible at the shore. Point 6 for the undisturbed water had molluscs' shells, birds and plant life.

In Figure 13, water quality parameters at various stations are presented. Figure 14 presents relationship between the three water parameters and the total daily motor vehicle counted during the sampling period. The correlation coefficients are computed and presented in Table (3).

\section{Discussions}

Table 3 Table 4 Figure 13 Figure 14

In Figure 12, the vehicle counts indicated higher numbers for Matatus and private cars. The change in the numbers recorded throughout the day indicated that the highest private car counts were recorded at around lunch hour. The flourishing fish eating business at the beach is an indicator that most of the private cars come to the beach for lunch and only have their cars washed as a value added service. As such they do not come to the beach specifically for washing. However, the matatus (commuter vehicles) had a different pattern. The highest counts were recorded after working hours, i.e., from 5pm when apparently the vehicles come down for washing at the close of the day's business.

In terms of $\mathrm{pH}$, Figure 13 indicates the motor vehicle washing points 2,4 , and 5 to have lower values. This can also be seen in Table 4. It is however indicative of how motor vehicle is contributing to acidity at the car washing points. Table (3) and Figure 14 indicate the daily mean $\mathrm{pH}$ of over 7 for all the sampled days except on 4th April 2005 when the vehicle count was low. The correlation coefficient of 0.77 indicate a strong correlation between the number of vehicles washed and the $\mathrm{pH}$ measured. The values of $\mathrm{pH}$ in car washing points ranged from 6.7-6.9 (Table 4). For the same area, Calamari et al. (1995) recorded values ranging from 7.9-8.9. This indicates a reduction of between 1.2-2.0. The reduction shows the possibility of direct motor vehicle washing causing an increase of acidity of the lake by $29 \%$.

Figure 13 indicate a higher value of total Phosphorus (TP) for the runoff entry point 1 (see also Table 4). This shows the incoming runoff from the open shed garages and bus park to be rich in-terms of nutrient of Phosphorus type. Figure 14 indicates a lower value of Phosphate on the 4th of April, a period which low number of vehicles were recorded as having been washed. The computed correlation coefficient of 0.77 shows a strong correlation between the total number of vehicles washed during the sampled period and the Phosphate in the lake waters. Small as they may be, these values contribute to the eutrophication of the lake as already pointed out by Okonga (2001) and Helmer and Espanhol (1997), leading to algae growth. LVEMP (2003) have estimated the total contribution of Phosphorus toeutrophication of the lake to be 32,050 tonnes/year. For Nyanza gulf, the region where we conducted our experiment, Njuru and Hecky (2005) have estimated the total Phosphorus for Kisumu to be $0.7 \mathrm{mg} / \mathrm{l}$. The avarage of the car washing points $(2,4$ and 5$)$ in these study from Table 4 is $0.38 \mathrm{mg} / \mathrm{l}$. In comparison to the value of Njuru and Hecky (2005), therefore, the contribution of direct car washing on the lake is about $54 \%$ of the total 
phosphorus polluting the lake at Kisumu. Runoff point 1 recorded above normal total phosphorus which could be attributed to the high concentration coming from the open shed garage.

High conductivity recorded at the point 1 (i.e., $301 \mu \mathrm{S} / \mathrm{cm}$ ) indicate the in-coming urban runoff to have high concentration of metals. These is expected as the garages are engaged with so much metal works and often deal with solutions and chemicals, most of which find their way into the lake. Figure 14 indicate the phosphate and conductivity values to be particularly low on the fourth of April, thus coinciding with the day when the number of cars washed was low. A strong correlation coefficient of 0.81 indicate a strong correlation between the total number of vehicles washed and the measured conductivity. For the same area, Njuru and Hecky (2005) indicate an average conductivity of $171 \mu \mathrm{S} / \mathrm{cm}$. The average of the car washing points $(2,4$ and 5$)$ in these study from Table 4 is $180.3 \mu \mathrm{S} / \mathrm{cm}$, i.e., an increase of about $9.3 \mu \mathrm{S} / \mathrm{cm}$ or a contribution of about $5.5 \%$ from direct car washing. For the runoff point 1 , this will be $76 \%$ increase in metallic substances from open shed garages. Undisturbed point 6 recorded a higher value of $19.8 \%$. This could be due to other Municipality waste, i.e., from a burst sewer.

Other impacts of motor vehicles related activities on the lake were also noted. For these, we could not undertake the absolute measurements but provided relative presentation. For instance, a casual observations at car washing sites reveal that the shore waters are now dirtier and greasier. The waste oils from the vehicles, dirt accumulated in transit are all washed into the lake. Some of the vehicles have leaking systems hence the oils or the fuels drip into the lake, causing further problems. As can be seen in Figure 8, the shores are no longer supporting the original vegetation or other small life forms, due to the conscious removal by the motor vehicle washers or possibly due to the decrease in the oxygen levels in the water occasioned by the oil covering the water surface. The oils washed off the vehicles (particularly petroleum vehicles, e.g., Figure 15) floats on the water surface forming a seal hence reducing the amount of oxygen available in the water for the survival of the flora and fauna. This would interfere with the amount of food available (see, e.g., Tet Leong, 2003) hence the trophic relationships at the particular site. This could explain the reason why there are no snail shells and predatory birds (like the Harmakop, in Figure 9) at the motor vehicle wash place.

Figure 15

Kichinjio beach is one of the breeding sites for some fish species and other aquatic life forms (Awange and Ong'ang'a 2006). The disturbance accompanied with oils in the water could have adversely affected them. In the study of the Zooplankton communities of some Tanzanian lake Victoria basin water bodies, Waya (2001) found that the structure and composition trends of zooplankton in the surveyed water bodies may be related to both intensity of predation by other marine animals and limitation by environmental factors, which may include the nature of the water bodies, food quality and quantity. This could be reason for the presence of shells at a site away from the motor vehicle wash and proves that pollution from point and non-point sources can significantly influence an ecosystem (Josef 2000; Okungu and Opango 2001). The wash consists of fluids such as oils, fuel, battery fluid and the dirt from inside as well as on the outer body of the vehicles. At the motor vehicle washing point for instance, it could not be possible to get a single mollusc's shell, indicating that the motor vehicle washing activity is already impacting negatively on the species composition of the beach.

The high number of vehicles recorded at the beach has also increased the bulk density at the shores; hence the ground at the motor vehicle washing is impermeable. The runoff from the town therefore goes directly into the lake without any filtration. The filter function of the natural wetland vegetation is fast being lost. The ground surface is now smooth and impermeable, hence reducing its suitability for burrowing and crawling faunal species.

It is evident that the urban run off is probably the most significant contributor to the accumulation of elemental pollutant load into the Lake. This further increases the accumulation of toxics in the food chain (Josef, 2000), and could also affect the nutrient ratio, resulting in the reduction of the food and introduction of some dominating species, like the Blue green algae which increases temperature and 
decreases transparency (see, e.g., Njuru 2001).

It is important to note, however, that the motor vehicle washing has increasingly become popular due to the other services offered. This includes the vibrant food kiosks specializing in fish business, boat riding and sight seeing. This could have an adverse effect on the long-term sustainability of the lake, as it will experience a rise in the concentration of pollutant elements. Comparing car washing points 2,4 and 5 to non-car washing points 3 and 6 , the floral and faunal composition has changed as can be seen in Figure 9. This indicate the physical impacts of motor vehicle washing in the lake.

From the vehicle counts, it can clearly be seen that the number of private vehicles to the beach is clearly the highest during lunch hour. Stopping motor vehicle washing in the lake is a priority activity. This calls for relocation of the activity to a distant location or the provision of waste water treatment before release into the lake. Relocation may negatively affect the fish eating business; hence the kiosk owners should be part of the wider strategy to rid the lake of direct motor vehicle washing. Corrective measures should therefore look not only at stopping motor vehicle washing bit but also how the other sectors operate, and how they affect each other. This calls for a holistic approach to the beach management. The food kiosks can be part of the solution, say through environmental awareness programs where the kiosk owners are made aware of the dangers that washing vehicles in the Lake causes. The kiosk owners could in turn make their customers aware of the threats.

It is also evident that the conventional runoff management is not environmentally friendly. This has seen the washing of pollutants directly into the lake. There is a need for the redesigning of the urban drainage to accommodate the provision for runoff filtration, oil scrapping and organic decomposition before its release into the lake. The provision of buffer vegetation between the urban center and the lake could be a major step towards the achievement of this goal. The protection and revamp of the wetlands around the lake recognizing their naturally occurring and important filter functions is key to the success of this initiative. They probably could be redesigned to include pollutant absorbing or tolerant species of plants.

\section{Conclusions}

The contribution of the motor vehicle washing to the lake's status can be classified as both direct and indirect. The direct effect is in terms of the pollutant load through the motor vehicle washing, while the indirect could be from run offs coming from vehicle repair sector ("jua kali"), petrol stations and main bus terminal. The indirect pollution from motor vehicle related runoff is significant compared to direct car wash. However, it may not be seen to be so, due to the diffused nature of their occurrence elsewhere and their transport into the lake through water and air medium. If these media are not addressed then the efforts to rid the lake of polluting vehicles may not be successful.

Acknowledgements: The first author wishes to acknowledge the support of DAAD (Germany Academic Exchange Program) for the financial support for the months of May-June that enabled partial undertaking of this study at Stuttgart University, Germany. The author is further grateful for the support and the good working atmosphere provided by his hosts Professors E. Grafarend and N. Sneeuw of the Department of Geodesy and Geoinformatics.

\section{References}

Aseto, O. \& Ong'ang'a, O. (2003). Lake Victoria (Kenya) and its environs: Resource, Opportunites and Challenges. (Africa Herald Publishing House: Kendu Bay, Kenya). 
Awange, J. L. \& Ong'ang'a, O. (2006). Lake Victoria: Ecology, Resources and Environment. (Springer-Verlag: Heidelberg)

Calamari, D., Akech, M. O., \& Ochumba, P. B. O. (1995). Pollution of Winam Gulf, Lake Victoria, Kenya: a case study for preliminary assessment. Lakes and Reservoirs: Research and Management, $1,89-106$

De Langen, M. \& Rustica, T. (2001). Productive and Livable cities. Guidelines for pedestrian and Bicycle Traffic in African Citie. (A.A. Publishers. Netherlands).

Helmer, R. \& Hespannol, I. (1997). Water Pollutionn Conntrol. A guide to the use of water quality management principles. (WHO/UNNEP)

Josef, L. (2000). Rapid Environmental Assessment: Lessons from Cities in the Developing World. Vol. 1. Methodology and Preliminary Findings. (Urban Management Programme, UNHCS, UNDP and the World Bank)

KCDS (2004). Kisumu City Development Strategy (2004-2009). Lake Victoria Region City Development Strategy For Improved Urban Environment And Poverty Reduction. " A leading transportation, communication and commercial hub in the Great Lakes Region offering great tourism and agro-investment opportunities"

KCEP (2005). Kisumu City Environmental Profile on Sustainable Urban Mobility. Kisumu City Council

LVEMP (2003). Lake Victoria Environmental Management Phase 1, Revised Draft Scientific Stocking Report. Progress during LVEMP 1 and challenges of the future. World Bank: Washington, $\mathrm{DC}$

Leong, S. T. (2003). An environmental approach for used oil management in Asian cities: a Bangkok's experience. Journal of Environmental Sciences, 15, 734 - 743

Njuru, P.G. (2001). An overview of the present status of Water Quality of Lake Victoria, Kenya: A limnological perspective. (Paper presented at LVEMP Regional Scientific Conference on 3rd to 7th December, Kisumu Kenya)

Njuru, P.G., \& Hecky, R. E. (2001). Nutrient concentrations in Nyanza Gulf, Lake Victoria, Kenya: light limits algal demand and abundance. Hydrobiologia, 534, 131-140

Odada, E., Olago, D., Kulindwa, K., Ntiba, M. \& Wandiga, E. (2004). Mitigation of environmental problems in Lake Victoria, East Africa: Causal chain and policy options analyzes. Royal Swedish Academy of Science, 33, 13-17

Okonga, J. R. (2001). A Review Of Estimation Of Rainfall And Evaporation Over Lake Victoria. (Paper presented at LVEMP Regional Scientific Conference on 3rd to 7th December, Kisumu Kenya)

Okungu, J. \& Opango, P. (2001). Pollution loads into Lake Victoria from the Kenyan catchment. (Paper presented at LVEMP Regional Scientific Conference on 3rd to 7th December, Kisumu Kenya)

Omoregi, E. \& Okunsebor, S. (2005). Levels of Biochemical constituents of fish associated with water dispersed fraction of used automobile lubricants. Journal of Environmental Science Part A: Toxic hazardous substance and Environmental Engineering and Health, 40, 157-166

Opiyo, T. (2004). Kisumu Sustainable Urban Mobility City Profile. (SUM City Profile, ITDG ) 
Pitt, R. (2001). Water Quality Problems Associated with Highway Development. (Paper presented at the Symposium on the Pollution of Water Sources from Road Run-Off held on March 19: Tel Aviv University Isreal)

Silva, E.I.L. \& Manuweera, L. (2004). Surface and Rainwater Chemistry in Sri Lanka - A Risk of Acidification. Asian Journal of Water, Environment and Pollution, 1, 79 - 86

Tamatamah, R. A., Hecky, R. E., Duthie, H. C. (2005). The atmospheric deposition of phosphorus in Lake Victoria (East Africa). Biogeochemistry, 73, 325-344

Waya, R. K. (2001). Zooplankton communities of some tanzanian lake victoria basin water bodies. (Paper presented at LVEMP Regional Scientific Conference on 3rd to 7th December, Kisumu Kenya)

Yitambe, A., Mwanzo, I., \& Mogere, S. (2005). Action Research on RTA in Kisii and Kisumu Cities, Western Kenya. Addressing Disaster Avoidance Strategies in Urban Areas. Technical Report. African Urban Risk Analysis Network (AURAN). 


\section{List of Figures}

Figure 1: Vehicle congestion and exhaust pollution

Figure 2: Eroded earthen roads and trenches at some of the beaches

Figure 3: Waste accumulation at bus termini

Figure 4: Wastes from vehicle repair known as Jua Kali

Figure 5: The spray painting process and wastes

Figure 6: Oil spills

Figure 7: Petrol station operations and the Caltex petrol depot at the lake side

Figure 8: Direct motor vehicle washing at Kichinjio beach

Figure 9: Difference between disturbed and undisturbed sites at Kichinjio beach

Figure 10: Daily changes in the vehicle count at the motor vehicle washing points for the sampled days

Figure 11: Daily averages number of vehicles washed at the beach

Figure 12: Average hourly change in vehicles being washed at the beach

Figure 13: Water parameters at various test stations

Figure 14: Correlation between water quality parameters and total number of daily vehicle count

Figure 15: Washing of petroleum vehicles at Kichinjio beach 
Table 1: Vehicle 12 hour Volume counts along various roads in the town

\begin{tabular}{|c|c|c|c|c|c|}
\hline Mode & Private cars & Taxis & Matatus & Buses & Trucks \\
\hline Totals & 71,174 & 20,311 & 28,800 & 1,259 & 10,356 \\
\hline
\end{tabular}

Table 2: Daily counts of vehicles washed in the Lake from 17th March to 28th April 2005

\begin{tabular}{|c|c|c|c|c|c|c|c|c|c|}
\hline $\begin{array}{c}\text { Type of } \\
\text { Vehicle }\end{array}$ & $\begin{array}{c}\text { Total Daily } \\
\text { Counts }\end{array}$ & & & & & & $\begin{array}{c}\text { Total by } \\
\text { type }\end{array}$ & $\begin{array}{c}\text { Daily } \\
\text { averages }\end{array}$ & $\%$ \\
\hline & 17 th $/ 3$ & 26 th $/ 3$ & 1 st $/ 4$ & 4 th $/ 4$ & 12 th $/ 4$ & 28 th $/ 4$ & & & \\
\hline Private cars & 95 & 101 & 98 & 66 & 97 & 96 & 553 & 92 & 34 \\
Pick ups & 36 & 34 & 32 & 16 & 33 & 33 & 184 & 31 & 12 \\
Matatu & 117 & 123 & 121 & 83 & 121 & 120 & 685 & 114 & 42 \\
Canters & 6 & 5 & 6 & 9 & 5 & 6 & 37 & 6 & 2 \\
Lorries & 25 & 23 & 21 & 24 & 21 & 19 & 133 & 22 & 8 \\
Tankers & 4 & 2 & 2 & 2 & 0 & 1 & 11 & 2 & 1 \\
Buses & 5 & 4 & 1 & 1 & 0 & 0 & 11 & 2 & 1 \\
\hline Totals & 288 & 292 & 281 & 201 & 277 & 275 & 1614 & 269 & 100 \\
\hline
\end{tabular}

Table 3: Mean daily values of water quality parameters

\begin{tabular}{|c|c|c|c|c|}
\hline Date & $\begin{array}{c}\text { Number of } \\
\text { vehicles }\end{array}$ & Mean $\mathrm{pH}$ & $\begin{array}{c}\text { Mean Total Phosphorus } \\
(\mathrm{mg} / \mathrm{l})\end{array}$ & $\begin{array}{c}\text { Mean Conductivity } \\
(\mu \mathrm{S} / \mathrm{cm})\end{array}$ \\
\hline $17 / 3 / 05$ & 288 & 7.1 & 0.5 & 209.7 \\
\hline $26 / 3 / 05$ & 292 & 7.2 & 0.8 & 229.2 \\
$1 / 4 / 05$ & 281 & 7.3 & 0.8 & 222.5 \\
$4 / 4 / 05$ & 201 & 6.9 & 0.2 & 168.7 \\
$12 / 4 / 05$ & 277 & 7.1 & 1.0 & 184.8 \\
$28 / 5 / 05$ & 275 & 7.0 & 0.8 & 217.5 \\
\hline Correlation & & $\mathbf{0 . 7 7}$ & $\mathbf{0 . 7 7}$ & $\mathbf{0 . 8 1}$ \\
\hline
\end{tabular}

Table 4: Daily average water quality for the six points along the beach

\begin{tabular}{|c|c|c|c|c|c|c|}
\hline $\begin{array}{c}\text { Sample } \\
\text { points }\end{array}$ & 1 & $\begin{array}{c}2 \\
\text { Car-wash 1 }\end{array}$ & 3 & $\begin{array}{c}4 \\
\text { Car-wash 2 }\end{array}$ & $\begin{array}{c}5 \\
\text { Car-wash 3 }\end{array}$ & 6 \\
\hline $\mathrm{pH}$ & 7.3 & 6.8 & 7.5 & 6.7 & 6.9 & 7.5 \\
Total Phosphorus $(\mathrm{mg} / \mathrm{l})$ & 2.4 & 0.3 & 0.3 & 0.2 & 0.6 & 0.5 \\
Conductivity $(\mu \mathrm{S} / \mathrm{cm})$ & 301.7 & 171.3 & 184.8 & 184.2 & 185.5 & 204.8 \\
\hline
\end{tabular}




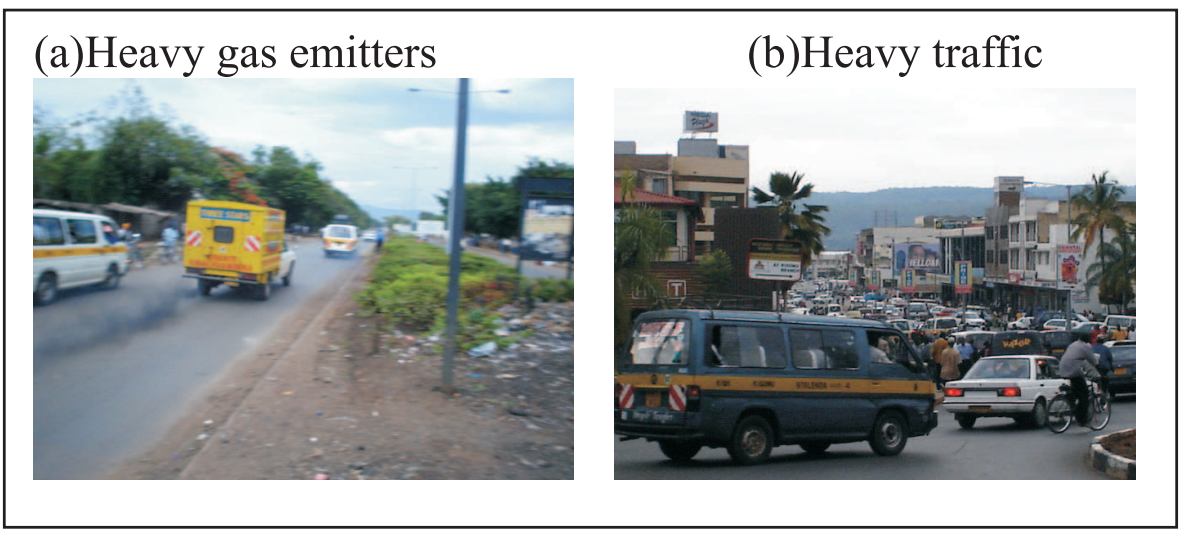

Figure 1: Vehicle congestion and exhaust pollution

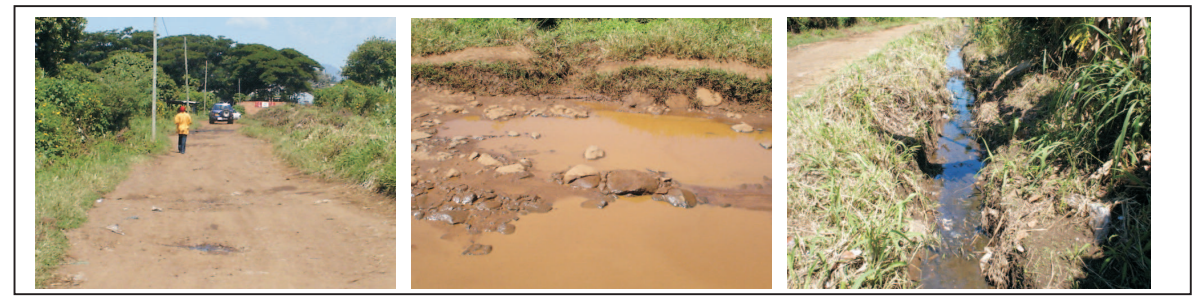

Figure 2: Eroded earthen roads and trenches at some of the beaches

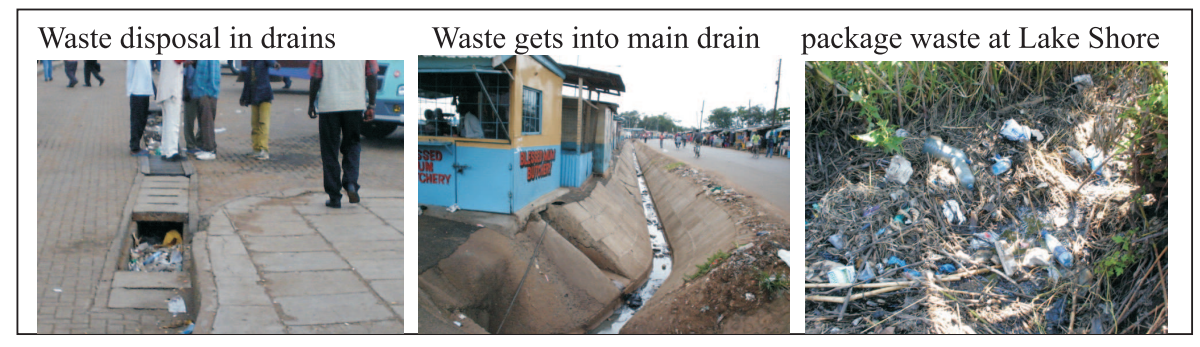

Figure 3: Waste accumulation at bus termini

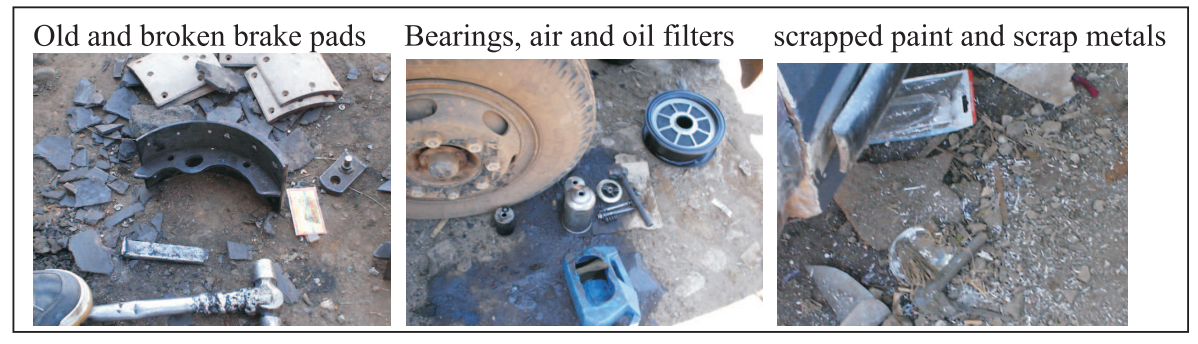

Figure 4: Wastes from vehicle repair known as Jua Kali 


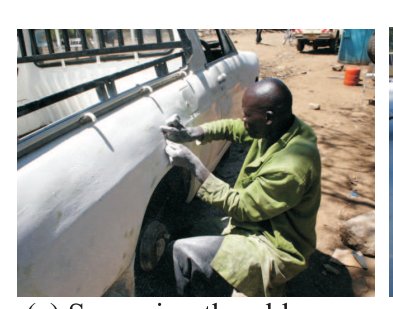

(a) Scrapping the old

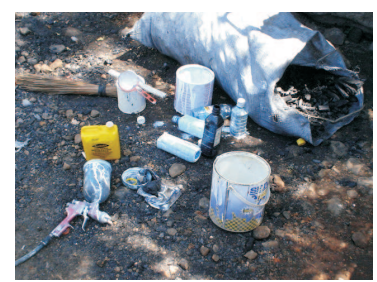

(d) Mixing chemicals

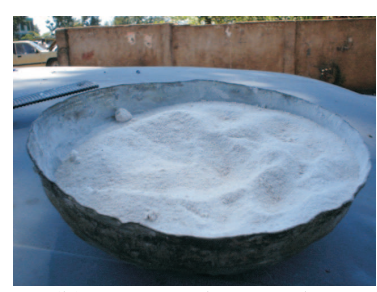

(b) Scrapped enamel

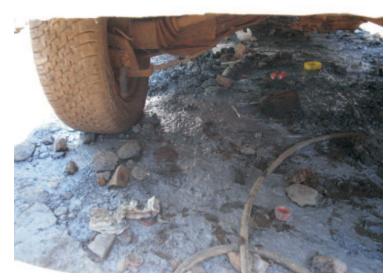

(e) Washing

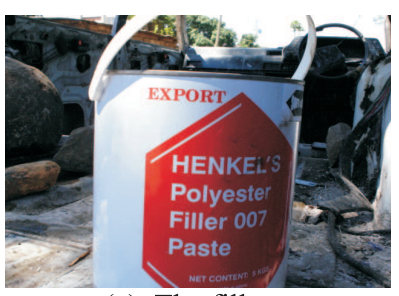

(c) The filler

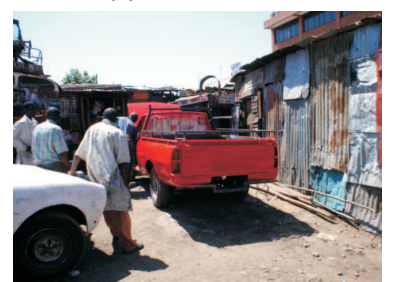

(f) Spray painting

Figure 5: The spray painting process and wastes

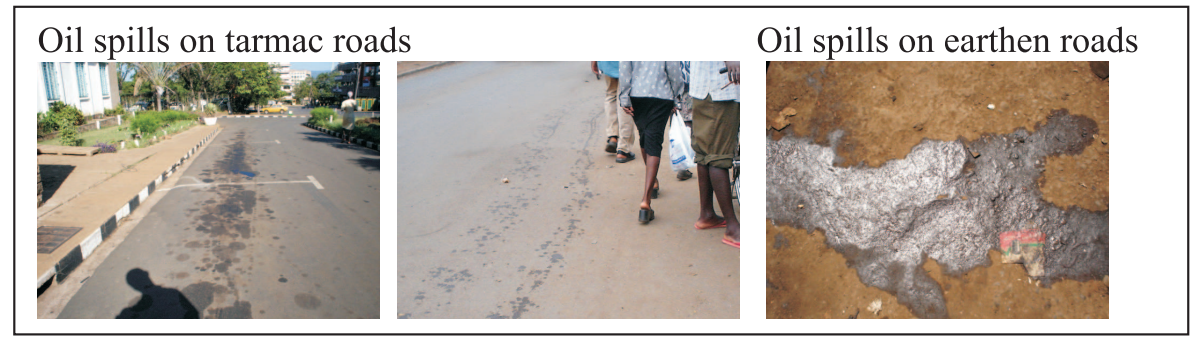

Figure 6: Oil spills

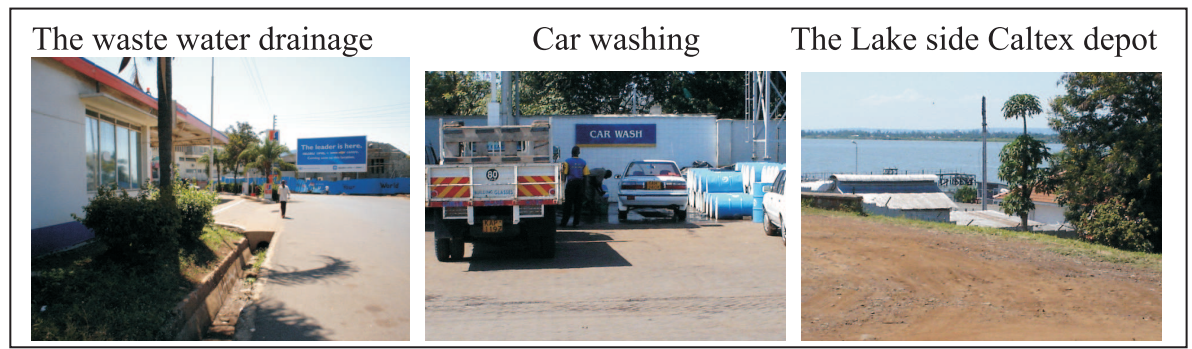

Figure 7: Petrol station operations and the Caltex petrol depot at the lake side 


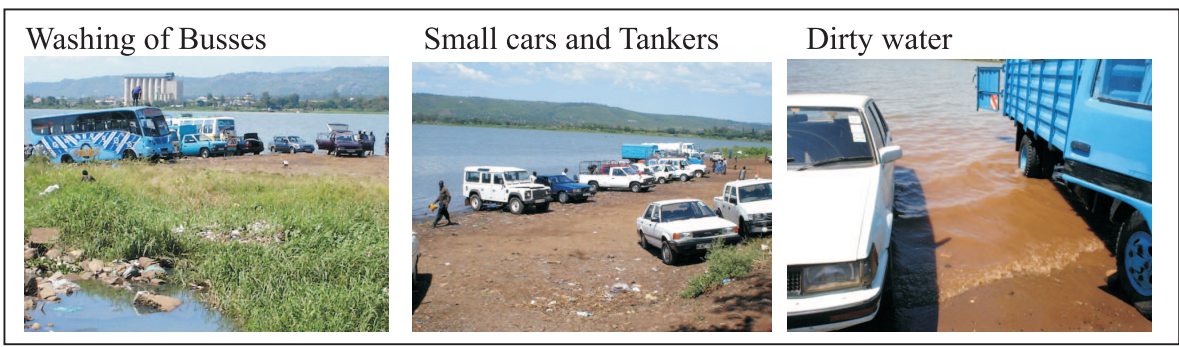

Figure 8: Direct motor vehicle washing at Kichinjio beach

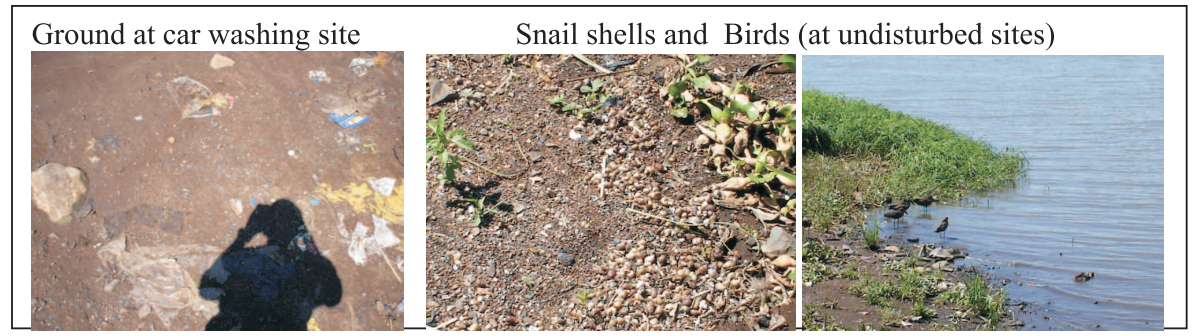

Figure 9: Difference between disturbed and undisturbed sites at Kichinjio beach

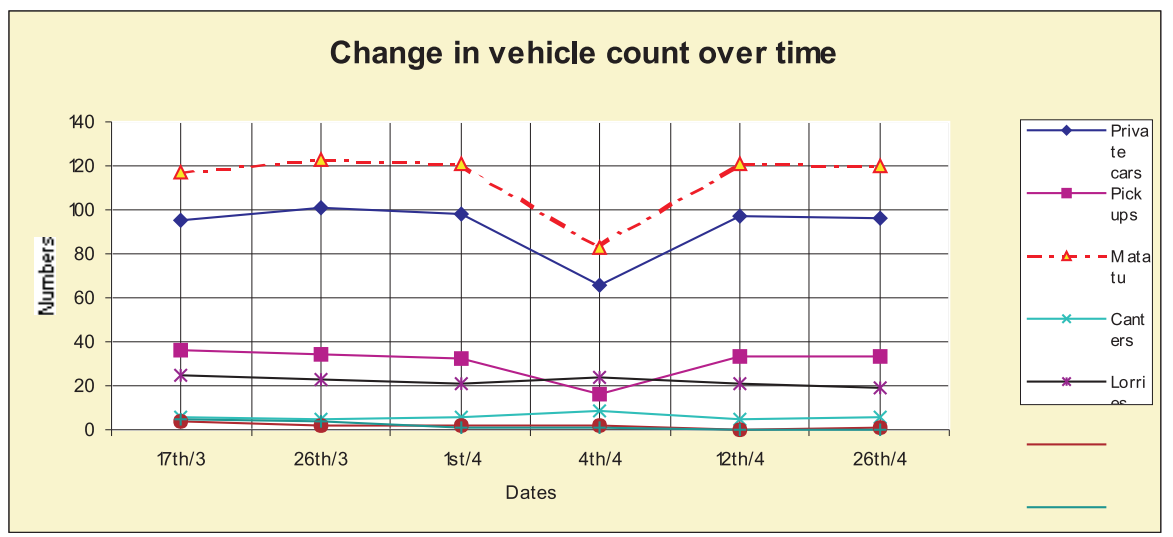

Figure 10: Daily changes in the vehicle count at the motor vehicle washing points for the sampled days 


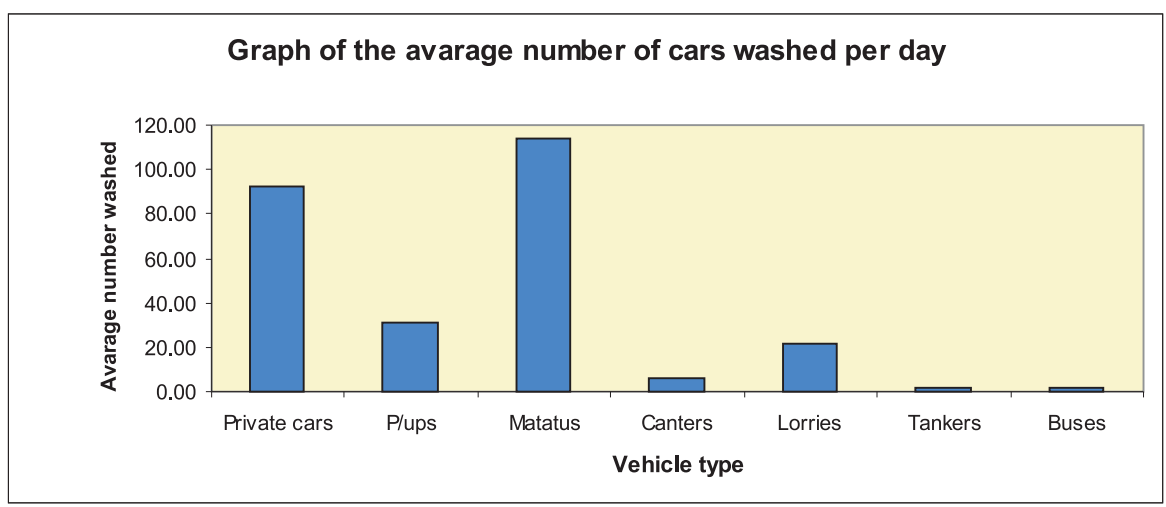

Figure 11: Daily averages number of vehicles washed at the beach

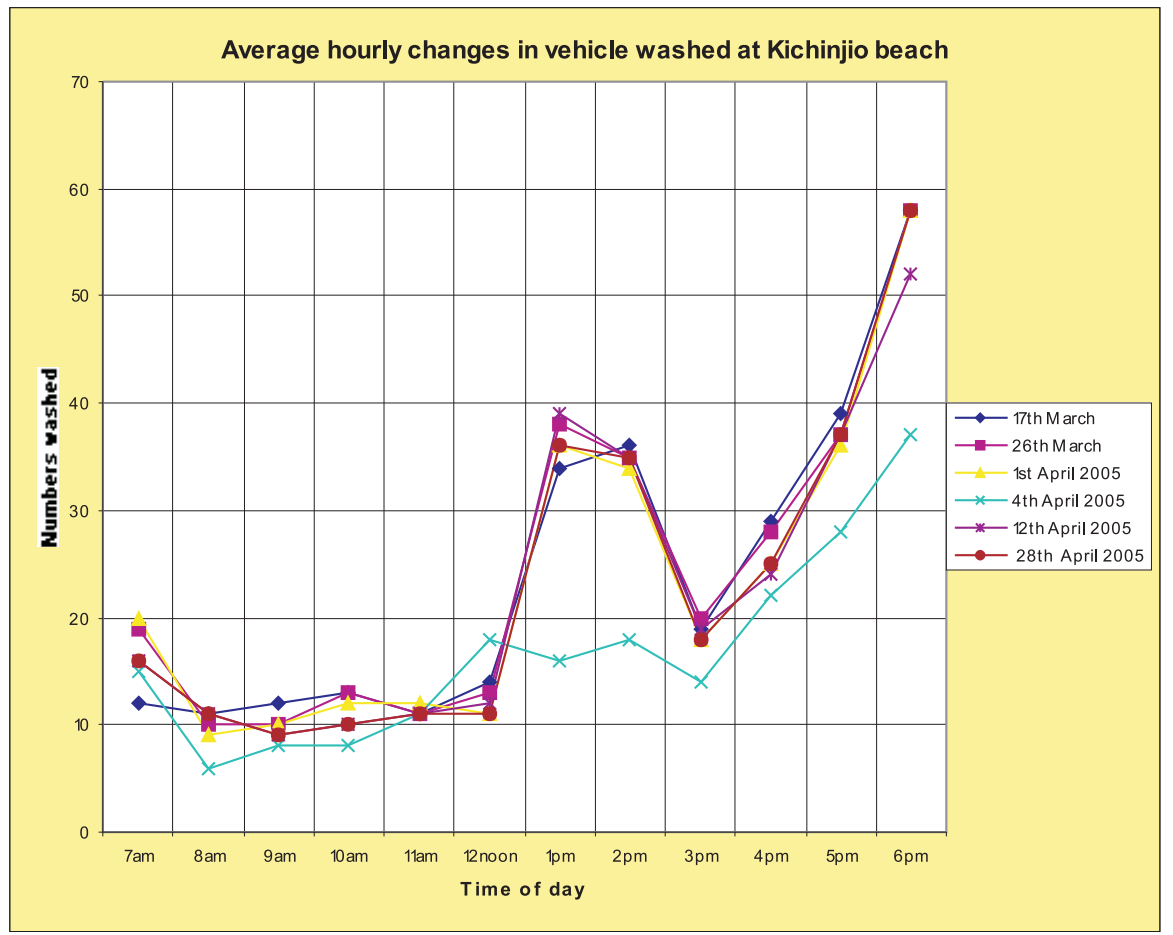

Figure 12: Average hourly change in vehicles being washed at the beach 


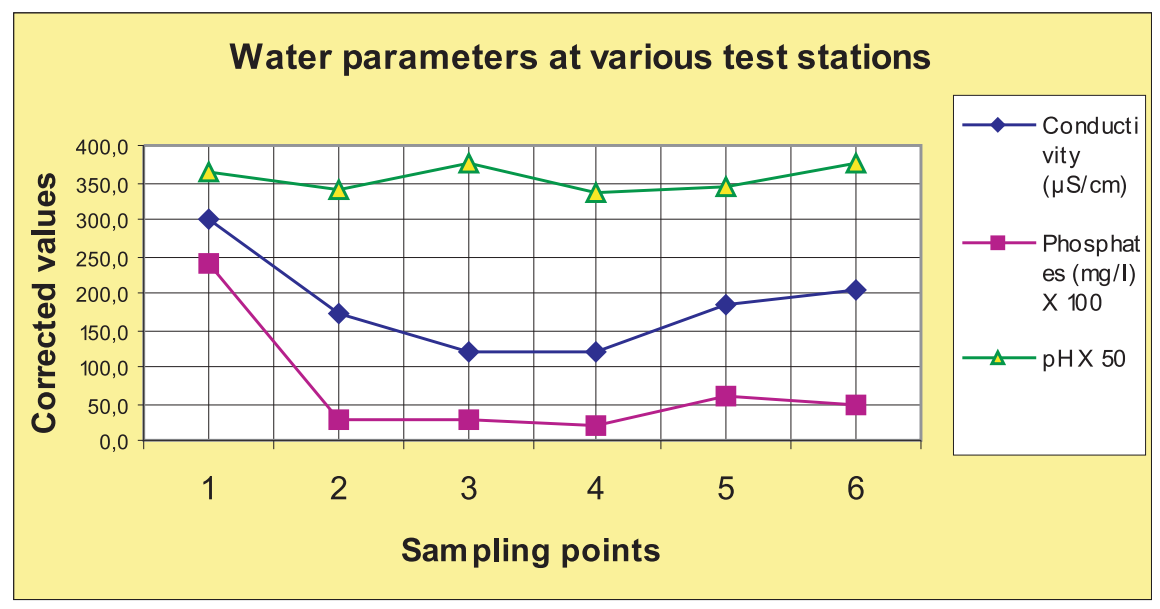

Figure 13: Water parameters at various test stations

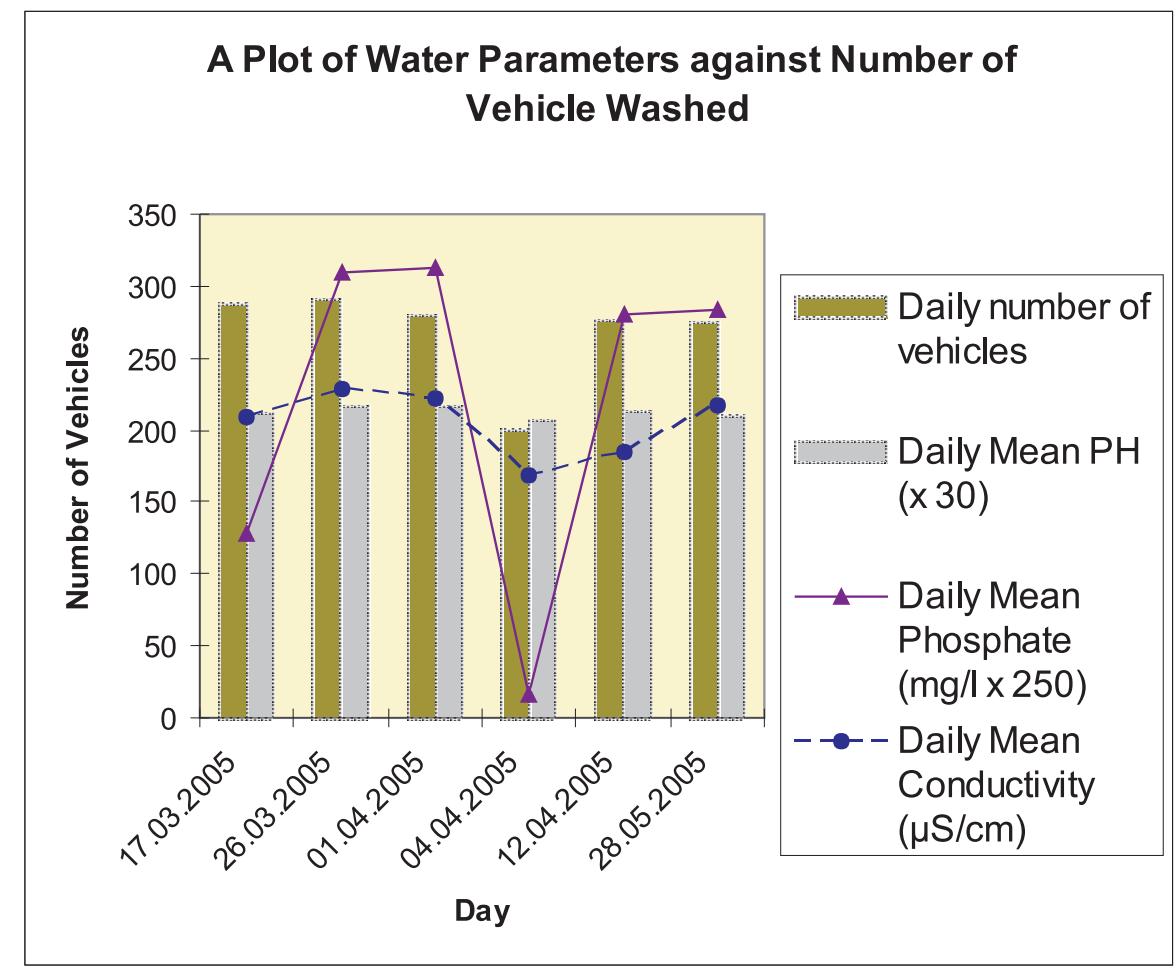

Figure 14: Correlation between water quality parameters and total number of daily vehicle count 


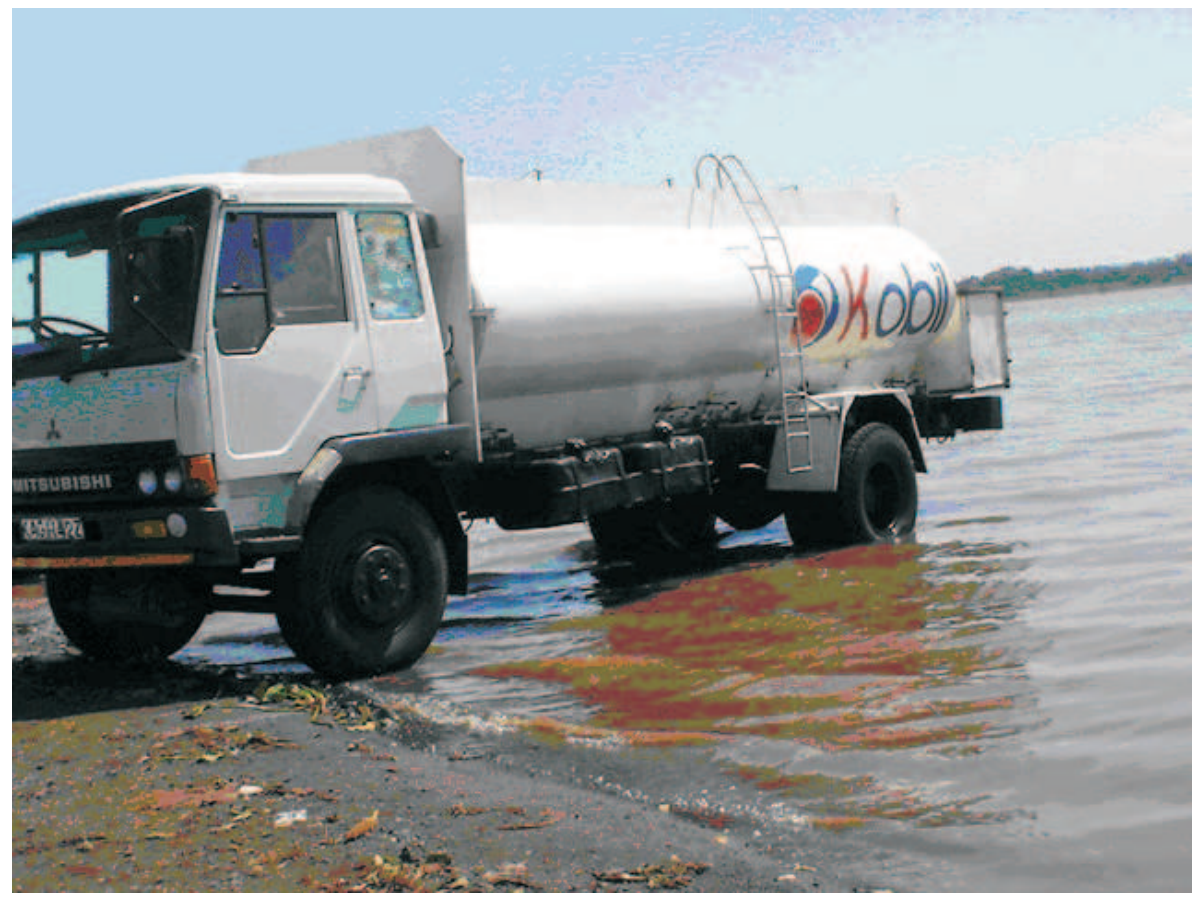

Figure 15: Washing of petroleum vehicles at Kichinjio beach 